\title{
Complications of Liver Biopsy
}

\author{
Abdullah Saeed Gozai Al-Ghamdi \\ Gastroenterology Unit, Medical Department, \\ King Fahad General Hospital, Jeddah, \\ Saudi Arabia
}

\section{Introduction}

Determination of the extent of progress of hepatic fibrosis and inflammation is important in clinical practice, where it may reflect the severity of liver disease and predict response to treatment. Percutaneous liver biopsy is the gold standard for grading and staging of liver disease which has been used for more than hundred years. The aim of this review is to know the safety and the complications related to such procedure in clinical practice. From experience and review of literatures, liver biopsy is frequently cited as a simple and safe procedure that may be performed at the bedside and as outpatient. Complications were more often experienced by those with relative contraindications and increased number of passes and if performed by less-experienced individuals. (1)

The complications after liver biopsy were reported to be more frequent in the presence of vascular liver lesions, biliary radical dilatation and in the presence of ascites.

Ultrasonography is a simple technique and recommended to detect vascular liver lesions, cystic lesions in the liver like echinococcal, biliary tree anatomy and to exclude presence of massive ascites which all is considered to be contraindications to liver biopsy and to determine the most suitable biopsy site. $(2,3)$

Before biopsy the patient should understand the whole procedure and the possible complications and to sign the consent form and also need to be cooperative during the procedure.

The history before the procedure is very important, like history of unexplained bleeding and family history of bleeding tendencies or blood diseases like hemophilia and the patient should be off medications that increase bleeding tendencies for certain time, like acetylsalicylic acid, non steroidal anti-inflammatory drugs and colpidogrel. (3) The operator should know about the coagulation profiles and platelets level of the patient before the procedure.

$1-5 \%$ of patients require hospitalization for complications and approximately $60 \%$ of complications occur within the first 2 hours following the procedure, and $96 \%$ within the first 24 hours. $(3,4,5)$

The morbidity and mortality related to liver biopsy was reported to be $0.08-0.34 \%$ and $0-0.19 \%$ respectively. (2)

Liver biopsy can be obtained by different techniques other than percutaneous, like Fine needle aspiration, trsnsjugular and laparoscopic especially if there are relative contraindications to percutaneous liver biopsy. 


\section{Percutaneous liver biopsy complications}

\subsection{Pain}

The most common complication is pain at biopsy site and shoulder and usually dull, mild and brief. A study using the visual analogue scale confirmed that the procedure is distinctly unpleasant, with $20 \%$ of the patients indicating that they experienced severe pain and approximately 1-5\% of the patients requiring admission from pain and most recover with only supportive measures. Ongoing, severe pain in the abdomen should alert the physician to the possibility of a more serious complication, such as bleeding or peritonitis. $(3,6,7,8,9,10)$

The overall frequency of pain requiring analgesics appears to be around $30-50 \%$ in patients not receiving prebiopsy medications. $(7,10)$

Outside of frank trauma to adjacent organs or severe bleeding, the mechanism of postbiopsy pain is uncertain and the biopsy site pain is likely to be a nociceptive pain that originates from the skin, the nociceptive innervated liver capsule, or both and high anxiety levels have been shown to exacerbate acute postoperative pain. $(10,11,12)$

The right-shoulder pain after liver biopsy is well known but has never been fully characterized. In other words, pain in the right shoulder begins, reaches its peak, and subsides together with the biopsy site pain. This may indicate that the right-shoulder pain is likely to be a viscerosomatic referred pain, rather than an indication of a severe complication, such as intraabdominal bleeding. (13)

It has been noticed in 2 studies that women tended to report higher pain level than men at all time points tested, the cause for the sex differences in pain perception is unknown. $(13,14)$ Analgesia before liver biopsy is usually avoided due to worries of masking pain that might indicative of abdominal symptoms and complications and still no consensus as to pain prevention and treatment for patients undergoing liver biopsy.

The practice of conscious sedation is variable, the midazolam-treated patients had a numerically lower mean pain score and significantly lower mean memory score than the untreated patients. (15)

It was noticed in the study by Brouillette DE et al, that patients receiving midazolam admitted to experiencing less discomfort during the biopsy procedure and had less memory for the procedure. More importantly, $79 \%$ of those receiving midazolam stated they would have little or no trouble undergoing a subsequent percutaneous liver biopsy as compared to $55 \%$ of those given saline. These data suggest that midazolam reduces subject anxiety and perceived discomfort before and during percutaneous liver biopsy produces partial amnesia for the biopsy experience and thereby may improve patient acceptance of follow-up liver biopsies. (16)

One possible way to improve pain control is to assess the anxiety level before the procedure, to adjust the dose of the anxiolytic drug accordingly, to add conscious sedation to those who are at a high level of stress, to infiltrate the biopsy site with long-acting local anesthetics, and to administer adequate analgesics for as long as needed. (13)

\subsection{Bleeding}

Of the serious complications, bleeding post liver biopsy is considered to be the most common cause. Bleeding is usually presented as subcapsular or parenchymal hematoma, free intraperitoneal hemorrhage, hemobilia or rarely hemothorax. 
Most complications and, in particular, hemorrhage and bile peritonitis, will be recognized within $4 \mathrm{hr}$ after biopsy. Delayed bleeding has been reported as late as 15 days after biopsy. (17)

It has been reported in two large studies of patients post liver biopsy that bleeding occur in $0.32-0.35 \%$ with morbidity related to hemorrhage of $0.24 \%$ and around $0.11 \%$ had mortality from severe bleeding. $(5,18)$

It has been found in some series that malignancy, cirrhosis, older age, and more than three passes were predictable risk factors for postbiopsy bleeding. $(5,8,18)$

Subclinical bleeding in the form of subcapsular or intrahepatic hematomas can be seen in up to $23 \%$ of patients and this is usually detectable by ultrasound 24 hours after biopsy. These hematomas are generally small and are not associated with significant hemodynamic compromise. (11)

The initial indications of bleeding are right upper quadrant abdominal pain that require analgesia and changes in vital signs with drop in blood pressure and rise in pulse rate.(19)

Most cases of fatal hemorrhage especially free intraperitoneal resulted from perforation of portal or hepatic veins or aberrant arteries. It may also occur as a result of a tear in the liver when the patient breathes deeply during the biopsy. ${ }^{20,21)}$ Free intraperitoneal hemorrhage can occur in $0.32 \%$ and this can be suspected clinically when the patient experienced abdominal pain, hypotension and tachycardia and can be confirmed by ultrasound or computed tomography. (22)

Hemorrhage usually stops spontaneously and patient is managed by measures to improve the hemodynamic status with intravenous fluids and blood products if needed. If bleeding is severe, selective angiography of the hepatic artery, besides establishing the diagnosis also provides the opportunity for embolisation or balloon occlusion of the segmental artery involved. (21)

Surgical exploration is indicated if hemodynamic instability persists despite the above measures and the laparotomy rate amongst patients who bled range from $6 \%$ to $25 \%$. $(21,23,24)$ The least common of the hemorrhagic complications is hemobilia and in one study by Piccinino F, et al reported 4 patients with hemobilia out of 86,276 liver biopsies.

Hemobilia is a term first used in 1946 by Sandblom to describe bleeding into the bile ducts.(22)

Hemobilia usually suspected when a post procedure fall in hemoglobin is associated with the classic triad of abdominal pain, hyperbilirubinemia, and unexplained gastrointestinal bleeding with average onset of approximately five days after biopsy. $(3,5,25)$ The bleeding is usually arterial in origin and can be venous in patients with portal hypertension. Biopsy can induce hematoma or pseudoaneurysm into bile duct and delayed bleeding can occur from gradual dissolution of that clot, while acute bleeding which is less common is secondary to simultaneous perforation of intrahepatic bile ducts and blood vessels. (25) Clinical presentation ranges from chronic anemia to rapid massive bleeding with hematemsis and/or melena and rarely patient may present with only hematochezia.

Diagnosis is usually suspected in patients with history of recent liver biopsy and most of endoscopic and radiological modalities including angiography can help in diagnosis.

Hemobilia can stop spontaneously and if patient still have continuous or intermittent bleeding then immediate selective angiography needed as diagnostic and therapeutic and considered to be the cornerstone of management. (26) 


\subsection{Biliary peritonitis}

Biliary peritonitis is the second most frequent serious complication after hemorrhage and can occur in $0.03 \%-0.22 \%$ and usually occur in the presence of biliary obstruction and can be in other patients secondary to gallbladder perforation. $(24,27)$ The patient is usually presented with severe abdominal pain and vasovagal hypotension immediately postbiopsy and this may be followed by fever, leukocytosis and ileus. Painless bile collection in the peritoneal cavity has been described. Radiolgical investigations like ultrasonography or computed tomography scan may identify an intra-abdominal collection of bile, and bile leaks may be demonstrated by ERCP. Conservative management is recommended with intravenous fluids, antibiotics and pain control and in case of clinical deterioration surgery may be needed. (27)

\subsection{Pulmonary complications}

Pulmonary complications post liver biopsy is considered to be rare and this can occur if needle biopsy passed in the costophrenic angle above the reflection of between the parietal and the visceral pleura. The patients can develop pneumothorax and hemothorax and also hydrothorax can be developed in cirrhotic patient with ascites by passage of ascitic fluid through the puncture site on diaphragm. $(20,21)$ The incidence of pneumothorax and/or pleural effusion occur in the range of $0.08-0.28 \%$ and the symptoms usually mild and pulmonary collapse not exceeding 10\%. (28) Hemothorax post liver biopsy is also rare with incidence of $0.18 \%-0.49 \%$ and this can be managed conservatively and rarely need thoracotomy. $(28,29,30)$

There is no role for angiogram with embolisation of diaphragmatic vessel for the treatment of hemothorax, as blood supply to the parietal diaphragm arises from vessels from the chest wall and abdominal wall. (31)

\subsection{Sepsis}

Sepsis and septic shock post liver biopsy is considered to be rare and can develop occasionally in patients with biliary obstruction. Inconsequential transient bacteremia has been reported in 5.8 to $13.48 \%$ of patients, therefore prophylactic antibiotics are not recommended for the routine use in patients undergoing liver biopsy, including those with risk factor for endocarditis. $(28,32,33)$

\subsection{Other complications}

Other rare complications after percutaneous liver biopsy include perforation of abdominal organs which is well tolerated and not require specific treatment, subphrenic abscess, and pancreatitis secondary to hemobilia. Needle track seeding following biopsy of malignant tumor of liver have been reported and some authors recommend liver biopsy only for patients who are not a candidate for surgical resection. $(21,34,35)$

\section{Fine needle aspiration}

Fine needle aspiration (FNA) is a technique used under ultrasound or CT scan guidance in those patients with focal hepatic lesions and at risk of bleeding. The diagnosis accuracy range from $80-95 \%$ and the cytologic findings that are negative for cancer do not rule it out. An important precaution is to choose the path of the needle in which normal tissue is 
interposed between the liver capsule and the lesion and to make as few needle passes as possible. FNA biopsy is generally a very safe procedure, even in patients with hemangiomas and echinococcal cysts and is associated with a low risk of seeding of the needle tract with malignant cells. $(3,36,37,38,39)$

\section{Transjugular liver biopsy}

Transjugular liver biopsy was first described experimentally in 1964 and in human subjects at 1967 and usually through transjugular catheterization of the hepatic veins. Liver tissue is obtained from within vascular system and this minimizes the risk of bleeding. $(40,41)$ It is performed in a vascular catheterization laboratory with video fluoroscopy equipment and cardiac monitoring because of the risk of cardiac arrhythmia as the catheter passes through the right atrium. The duration of the procedure is between 30 and 60 minutes and adequate specimen was obtained in $97 \%$. $(3,42)$ Although not easy, this technique is safe and preferable in the management of selected patients with coagulopathy and risk of bleeding, moderate to severe ascites, massive obesity, small cirrhotic liver and patients with suspected vascular tumor. (43)

The total complication rate in 7469 transjugular liver biopsies reported in 62 series published between 1978 and 2006 was 7.1\%, 3.5\% were related to liver puncture while 3.3\% were not. (43) The major complications of transjugular liver biopsy are rare and occur between 0.01 to $0.2 \%$ and may include large hepatic hematoma, intraperitoneal hemorrhage, inferior vena cava perforation, renal vein perforation, ventricular arrhythmia, pneumothorax and respiratory arrest. The patients may also get some minor complications like pyrexia, abdominal pain, neck hematoma, transient Horner's syndrome, transient dysphonia, subclinical capsular perforation, formation of a fistula from the hepatic artery to the portal vein or the biliary tree and all these complications can occur in $0.01-1.6 \%$. Deaths can occur in $0.1 \%$ of patients mainly secondary to intraperitoneal hemorrhage or ventricular arrhythmia. (43)

\section{Laparoscopic liver biopsy}

A laparoscopic liver biopsy is another method for obtaining liver tissue and may be done solely or may be part of another operative procedure and this allows direct inspection of the liver surface prior to the biopsy, demonstrate cirrhosis in almost all patients and allow direct compression of the biopsy site if bleeding is excessive. (44)

It has also been used in centers where access to transjugular liver biopsy is not available, for patients with abnormal clotting parameters, and also in patients who have a combination of a focal liver lesion and a coagulopathy where a histological diagnosis is essential in the management of that patient. (42) The complications of laparoscopic liver biopsy include vasovagal reaction, seizure, abdominal wall hematoma, abdominal viscus perforation, hemobilia, splenic laceration, bleeding and prolonged abdominal pain. (45)

\section{Conclusion}

We conclude that in properly selected patients and after exclusion of risk factors for complications, liver biopsy is considered to be safe outpatient procedure and still the gold standard method and definitive diagnostic test for difficult cases of liver diseases. 


\section{References}

[1] Perrault J, McGill DB, Ott BJ, et al. liver biopsy: complications in 1000 inpatients and outpatients. Gastroenterology 74 (1), 1978.

[2] Froehlich F, Lamy O, Fried M, Gonvers JJ. Practice and complications of liver biopsy. Results of a nationwide survey in Switzerland. Dig Dis Sci. Aug 1993;38 (8):1480-4

[3] Bravo, AA, Sunil GS, Chopra S. Liver biopsy. NEJM 344 (7), 2001.

[4] van Leeuwen DJ, Wilson L, Crowe DR. Liver biopsy in the mid-1990s: questions and answers. Semin Liver Dis 1995;15:340-59.

[5] Piccinino F, Sagnelli E, Pasquale G, Giusti G. Complications following percutaneous liver biopsy: a multicentre retrospective study on 68,276 biopsies. J Hepatol 1986;2:165-73.

[6] Crockett SD, Kaltenbach T, Keeffe EB. Do we still need a liver biopsy? Are the serum fibrosis tests ready for prime time? Clin Liver Dis 2006;10:513-34.

[7] Castera L, Negre I, Samii K, Buffet C. Pain experienced during Percutaneous liver biopsy. Hepatology 1999;30:1529-30.

[8] Janes C.H., Lindor K.D.. Outcome of patients hospitalized for complications after outpatient liver biopsy. Ann Intern Med 1993; 118:96-98.

[9] Perrault J., McGill D.B., Ott B.J., Taylor W.F. Liver biopsy: Complications in 1000 inpatients and outpatients. Gastroenterology 1978;74:103-106.

[10] Caldwell S H. Controlling pain in liver biopsy, or "we will probably need to repeat the biopsy in a year or two to assess the response". A J Gastroenterol 96 (5), 2001.

[11] Minuk G.Y., Sutherland L.R., Wiseman D.A., et al. Prospective study of the incidence of ultrasound-detected intrahepatic and subcapsular hematomas in patients randomized to 6 or 24 hours of bed rest after percutaneous liver biopsy. Gastroenterology 1987;92:290-293.

[12] Hartmann H, Beckh K. Nerve supply and nervous control of liver function. In: Mclntyre N, Benhamou JP, Bircher J, eds. Oxford textbook of clinical hepatology. Vol 1, sections 1-13. Oxford: Oxford University Press, 1993:93.

[13] Eisenberg E , Konopniki M , Veitsman E , et al. Prevalence and characteristics of pain induced by percutaneous liver biopsy . Anesth Analg . 2003;96:1392-1396.

[14] Cadranel J, Rufat P, Degos F. Practices of liver biopsy in France: results of a prospective nationwide survey. Hepatology 2000;32:477-80.

[15] Alexander JA, Smith BJ. Midazolam sedation for Percutaneous liver biopsy. Dig Dis Sci 1993;38:2209-11.

[16] Brouillette DE, Yoo YK, Chien MC, et al. Use of midazolam for percutaneous liver biopsy. Dig Dis Sci 1989;34:1553-8.

[17] Jacobs W H; Goldberg S B. Statement on outpatient percutaneous liver biopsy. Digestive diseases and sciences 1989;34 (3):322-3.

[18] McGill DB, Rakela J, Zinsmeister AR, Ott BJ. A 21-year experience with major hemorrhage after percutaneous liver biopsy. Gastroenterology 1990; 99:1396-400.

[19] Mahal AS, Knauer CM, Gregory PB. Bleeding after liver biopsy. West J Med. 1981 Jan;134 (1):11-14.

[20] Zamcheck N, Sidman RI.. Liver biopsy I. Its use in clinical and investigative medicine. N Engl J Mcd 1953; 249: 1020.

[21] Chuah SY. Liver biopsy - past, present and future. Singapore Med J 1996;37:86-90. 
[22] Sandblom P. Hemorrhage into the biliary tract following trauma-"traumatic hemobilia". Surgery 1948; 24:571-86.

[23] Lindner H. Grenzen und Gefuhren der perkutanen Leberbiopsie mit der MenghiniNadel. Erfahrungen bei 80,000 leberbiopsien. Dtsch Med Wochenschr 1967; 39: 1751-7.

[24] Terry R. Risks of needle biopsy of the liver. Br Med J 1952; 1:1102-5.

[25] Lichtenstein DR, Kim D, Chopra S. Delayed massive hemobilia following percutaneous liver biopsy: treatment by embolotherapy. Am J Gastroenterol 1992;87:1833-8.

[26] Dang S, Neelima V, Atiq M, Olden KW, Aduli F: Hemobilia after Percutaneous Liver Biopsy Presenting as Hematochezia: A Rare Complication of a Commonly Performed Procedure. Chir Gastroenterol 2008;24:313-315.

[27] Ruben, RA, Chopra, S. Bile peritonitis after liver biopsy: Nonsurgical management of a patient with an acute abdomen: A case report with review of the literature. Am J Gastroenterol 1987; 82:265.

[28] Campbell MS, Jeffers LJ, Reddy KR. Liver biopsy and laparoscopy. In: Schiff L, Schiff ER. eds. Diseases of the Liver. 10th ed. Lippincott William \& wikins. 2007: 62-83.

[29] Majid AA. Hemorrhage from the diaphragm: an unusual cause of hemothorax after liver biopsy. Am J Gastroenterol 1990;85:104-5.

[30] Chahal PS, Ready J. Hemothorax after percutaneous liver biopsy: an unusual complication. Am J Gastroenterol 2002; 97:1068-9.

[31] Yeo WT, Tan LK, Dan YY, et al (2008) Delayed bleeding after liver biopsy: a dreaded complication. Singapore Med J. 49: 76-80.

[32] McClosky RV, Gold M, Waser E. Bacteremia after liver biopsy. Arch Intern Med 1973;132:213-215.

[33] LeFrock JL, Ellis CA, Turchik JB, et al. Transient bacteremia associated with percutaneous liver biopsy. J Infect Dis 1975;131:S105-S107.

[34] John TG,Garden OJ. Needle track seeding of primary and secondary liver carcinoma after percutaneous liver biopsy. IIPB Surg 1993; 6:199-203.

[35] Evans GH, Harries SA, Ilobbs KE.Safety of and necessity of needle biopsy of liver tumou rs.Heuer ]. Lancet 1987; i: 620.

[36] General principles. In: Lee RG. Diagnostic liver pathology. St. Louis: Mosby-Year Book, 1994:1-21.

[37] Eisenberg PJ, Bolland GW, Mueller PR. Introduction. In: Pitman MB, Szyfelbein WM, eds. Fine needle aspiration biopsy of the liver: a color atlas. Boston: ButterworthHeinemann, 1994:3-5.

[38] Smith EH. Complications of percutaneous abdominal fine-needle biopsy: review. Radiology 1991;178:253-8.

[39] Drinkovic I, Brkljacic B, Two cases of lethal complications following ultrasound-guided percutaneous fine-needle biopsy of the liver. Cardiovasc Intervent Radiol. 1996; 19 (5):360-3.

[40] Dotter CT. Catheter biopsy. Experimental technique for transvenous liver biopsy. Radiology 1964;82:312-314.

[41] Hanafee W, Weiner M. Transjugular percutaneous cholangiography. Radiology 1967;88:35-9.

[42] Grant A, Neuberger J (1999) Guidelines on the use of liver biopsy in clinical practice. British Society of Gastroenterology. Gut 45 Suppl 4: IV1-IV11. 
[43] Kalambokis G, Manousou P, Vibhakorn S, et al. Transjugular liver biopsy - indications, adequacy, quality of specimens, and complications - a systematic review. Journal of Hepatology. 2007;47 (2):284-294

[44] Pagliaro L, Rinaldi F. Craxi A, Di Piazza S, Filippazzo G, Gatto G, et al. Percutaneous blind biopsy versus laparoscopy with guided biopsy in diagnosis of cirrhosis: a prospective randomized trial. Dig Dis Sci 1983; 28: 39-43.

[45] Vargas C, Jeffers LJ, Bernstein D, et al. Diagnostic laparoscopy: a 5-year experience in a hepatology training program. Am J Gastroenterol 1995;90:1258-62. 


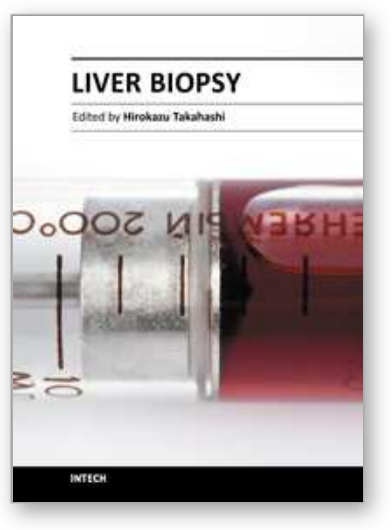

\author{
Liver Biopsy \\ Edited by Dr Hirokazu Takahashi
}

ISBN 978-953-307-644-7

Hard cover, 404 pages

Publisher InTech

Published online 06, September, 2011

Published in print edition September, 2011

Liver biopsy is recommended as the gold standard method to determine diagnosis, fibrosis staging, prognosis and therapeutic indications in patients with chronic liver disease. However, liver biopsy is an invasive procedure with a risk of complications which can be serious. This book provides the management of the complications in liver biopsy. Additionally, this book provides also the references for the new technology of liver biopsy including the non-invasive elastography, imaging methods and blood panels which could be the alternatives to liver biopsy. The non-invasive methods, especially the elastography, which is the new procedure in hot topics, which were frequently reported in these years. In this book, the professionals of elastography show the mechanism, availability and how to use this technology in a clinical field of elastography. The comprehension of elastography could be a great help for better dealing and for understanding of liver biopsy.

\title{
How to reference
}

In order to correctly reference this scholarly work, feel free to copy and paste the following:

Abdullah Saeed Gozai Al-Ghamdi (2011). Complications of Liver Biopsy, Liver Biopsy, Dr Hirokazu Takahashi (Ed.), ISBN: 978-953-307-644-7, InTech, Available from: http://www.intechopen.com/books/liverbiopsy/complications-of-liver-biopsy

\section{INTECH}

open science | open minds

\author{
InTech Europe \\ University Campus STeP Ri \\ Slavka Krautzeka 83/A \\ 51000 Rijeka, Croatia \\ Phone: +385 (51) 770447 \\ Fax: +385 (51) 686166 \\ www.intechopen.com
}

\author{
InTech China \\ Unit 405, Office Block, Hotel Equatorial Shanghai \\ No.65, Yan An Road (West), Shanghai, 200040, China \\ 中国上海市延安西路65号上海国际贵都大饭店办公楼 405 单元 \\ Phone: +86-21-62489820 \\ Fax: +86-21-62489821
}


(C) 2011 The Author(s). Licensee IntechOpen. This chapter is distributed under the terms of the Creative Commons Attribution-NonCommercialShareAlike-3.0 License, which permits use, distribution and reproduction for non-commercial purposes, provided the original is properly cited and derivative works building on this content are distributed under the same license. 